\title{
Modeling of transportation logistics processes for the urban environment
}

\author{
Petr Romanov ${ }^{1}$, and Irina Romanova ${ }^{2, *}$ \\ ${ }^{1}$ Kolomna Institute (branch) of "Moscow Polytechnic University", 408, Oktiabrskoy Revolutsii Str., \\ Moscow Region, Kolomna,140402, Russia \\ ${ }^{2}$ K.G. Razumovsky Moscow State University of technologies and management (the First Cossack \\ University), 73, str. Zemlyanoy Val, Moscow, 109004, Russia
}

\begin{abstract}
The article deals with the approach to modeling the road transport movement in large cities (with a population of over 100 thousand people) for the delivery of goods from a large warehouse to stores belonging to a trading network company, with the task of optimizing these movements. The main purposes of this optimization task are: to reduce the transportation time; to conduct a rational distribution of vehicles; to reduce the number of required vehicles involved in these transportations; to reduce operating costs for the maintenance of vehicles. The problem statement and its solution on the basis of heuristic algorithms of the Traveling Salesman Problem are given. The article presents a comparative analysis of the most popular methods for solving the Traveling Salesman Problem (Greedy Approach, Modified Greedy Approach, Minimum Spanning Tree, Monte Carlo Simplification Model, Ant Colony Optimization, Algorithm of Little) on the basis of experimental research and simulation. As a result of the analysis, it is proposed to use the Algorithm of Little for optimizing of road transport movement in the delivery of goods. The article provides an example of solving a specific problem using the developed calculation procedure and a computer program "Traveling Salesman Problem" (developed in Pascal in the software environment Delphi 7).
\end{abstract}

\section{Introduction}

The configuration of cities and their convenience for life depend on transport factors, one of the most important is motorization. At the same time, the combination of a healthy economy and stable social relations with a humanitarian-oriented urban environment, practically unattainable in "automobile-dependent" cities, was recognized as a sign of a city convenient for life. In order to improve traffic conditions and prevent chronic congestion on the road network, various transport policy measures are applied, in particular modern traffic management methods that allows to use available resources of the road network the most effectively. In this regard, it is important to optimize logistics flows in urban environments.

Material flow is fundamental in logistics. It is formed as a result of transportation, storage and other material operations with raw materials, semi-finished products and finished

\footnotetext{
*Corresponding author: i-p-romanova@yandex.ru
} 
products, from the primary source of raw materials up to the final consumer. Material flows include: transportation of raw materials and semi-finished products from suppliers and products of work in progress within the enterprise, activities related to the transshipment of goods from one transport vehicle to another, placement and storage of goods, selection, packaging and storage, further transportation to customers (operational and sales work) [1, 2].

Management of material flow, like any other object, consists of two parts: decisionmaking and implementation of the decision. Transport logistics includes transportation of goods from the supplier to the consumer, from the enterprise to the warehouse, from the warehouse to the warehouse, delivery from the warehouse to the consumer. The specific tasks of transport logistics include: reducing of transportation of goods time; rational distribution of transport vehicles [3].

To solve one of the problems of transport logistics - delivery of goods from the warehouse to the consumer - in modern conditions mainly road transport is used. In recent years chain stores that sell a variety of products are widespread. Often, the company has up to ten or more stores in one city with a population of 100-150 thousand people and one large warehouse in or near this city. There are goods that need to be delivered daily or several times a week in small batches to each of the stores of the network (bread, perishable food, fruits etc.). Therefore delivery of goods from a warehouse to shops is carried out by means of heavyload cars, often with trailers [4].

One of the tasks of transport logistics - reducing the transportation time - can be solved by optimizing of road transport movement during delivery of goods from the warehouse to the stores. On the other hand, optimization allows to solve another problem of transport logistics - rational distribution of transport vehicles. This will reduce the required number of vehicles involved in these transportations, and, consequently, reduce the cost of fuel and lubricants, spare parts, personnel maintenance. Therefore, the optimization of the route of the road transport in the delivery of goods is a very important task. To solve it, it is necessary to reduce the time of the road transport movement between the warehouse and shops and between shops [5].

It should be noted that this problem belongs to the field of combinatorial optimization, and is also studied in the decision theory and operations research and is known as the Traveling Salesman Problem. It is a problem of assignments with additional constraints that allow to exclude incomplete closed routes from the optimal solution $[6,7]$.

\section{Experimental section}

To solve the problem of optimizing of road transport movement in the delivery of goods by the mathematical model of the Traveling Salesman Problem, it is necessary to make a comparative analysis of methods for solving this problem for the subsequent selection of the most effective of them.

The Traveling Salesman Problem is formulated as follows: the traveling salesman, coming out of the 1 st city, must visit the city $2,3,4, \ldots, n$ once and go back to the 1 st city. Distances between cities are known. It is necessary to find the order of bypassing the cities so that the closed path (cycle, route) of the traveling salesman must be the shortest. City numbered $\mathrm{j} \in \mathrm{T}=(1,2,3, \ldots, \mathrm{n})$ and the traveling salesman path is described by a cyclic permutation $\mathrm{t}=\left(\mathrm{j}_{1}, \mathrm{j}_{2}, . ., \mathrm{j}_{\mathrm{n}}, \mathrm{j}_{1}\right)$, where $\mathrm{j}_{1}, \ldots, \mathrm{j}_{\mathrm{n}}$ are different numbers and $\mathrm{j}_{1}$ is repeated at the beginning and at the end and shows that the permutation is looped. The distances between pairs of vertices $\mathrm{C}_{\mathrm{ij}}$ form a matrix $\|\mathrm{C}\|$. It is required to find such cycle $\mathrm{t}$ at which the functional is minimized:

$$
L=L(t)=\sum_{k=1}^{n} C_{j_{k} j_{k+1}} \rightarrow \min
$$


From the mathematical formulation of the problem follow the conditions:

1) Since $C_{i j}$ are the distances, then they must be non-negative and symmetric, i.e. for all $\mathrm{i}, \mathrm{j}\left(C_{j j}=\infty\right.$ means a ban on loops in a cycle):

$$
\begin{gathered}
j \ni T: C_{i j} \geq 0 ; C_{j j}=\infty \\
C_{i j}=C_{j i}
\end{gathered}
$$

and satisfy the triangle-inequality, i.e. for all:

$$
C_{i j}+C_{j k}=C_{i k}
$$

Usually two types of problem are considered: symmetric problem when condition (3) is satisfied, and asymmetric - otherwise. It is considered that conditions (2) - (4) are met by default $[8,9]$.

2) This condition applies to the number of all possible routes. In the asymmetric task all routes, $t=\left(j_{1}, j_{2}, . ., j_{n}, j_{1}\right)$ and $t^{\prime}=\left(j_{1}, j_{n}, . ., j_{2}, j_{1}\right)$, have different lengths and therefore both are taken into account. The number of different routes will be (n-1)!.

The general formulation of the Traveling Salesman Problem and most of its special cases belongs to the class of NP-complete problems, and, on this basis, the algorithms for solving the problem are divided into exact and approximate [10].

Exact algorithms produce an optimized full search of options. Sometimes they allow to find solutions soon enough, but basically there is a search of all $n$ ! routes. For that reason exact algorithms are appropriate only for small problem size. The Traveling Salesman Problem is a transcalculating problem. This means that if there are more than 66 points in the bypass route, it can be solved by brute force even with the help of modern computer technology for a very long time (about several billion years) [11].

Approximate methods for solving the Traveling Salesman Problem are heuristic methods and are quite effective, because they reduce the full search of routes. In many of them they find not an effective route, but a basic route, i.e. an approximate solution. And then this basic route is improved $[12,13]$.

Currently, there are quite a lot of methods (algorithms) for solving the Traveling Salesman Problem: explicit enumeration (Brute Force, Greedy approach, Divide and conquer etc), deterministic methods (Branch and Bound Algorithm (algorithm of Little), Cutting Plane Method, Dynamic Programming etc.), stochastic methods (Evolutionary Computation, Random search Walk, Monte Carlo Simplification Model etc.), combined methods (Ant Colony Optimization, Memetic Algorithms, Genetic algorithms, Tabu-search, Simulated Annealing, Firefly Algorithm etc.) [14]. Permutations, loop reversal and combined methods are often used to improve the basic route $[15,16]$.

The task of optimizing of road transport movement in the delivery of goods to the network of chain stores from the warehouse is formulated as follows.

To provide a network of chain stores in the city the vehicle need to transport goods (food and household) consistently stopping in all stores. At first it must to load the goods in the warehouse of the company, which owns these stores. Then, the vehicle must deliver the goods to the stores, stopping in each of them once in any order, and return to the warehouse. Distances between shops are known. This takes into account not only the length of routes through the streets of the city, but also in the form of coefficients introduced in the distance between the shops possible delays (stops at traffic lights, etc.). It is required to determine the order of arrival in stores, in which the vehicle should deliver the goods, which provide the shortest closed route of moving the vehicle around the city. The mathematical formulation of the problem is described by formulas (1) - (4).

The proposed calculation algorithm includes the following steps to solve the problem: 
1. To enter the source data as distances between stores and between stores and the warehouse.

2. To select the method (algorithm) to solve the problem.

3. To define the route using the selected method and to calculate the route length.

4. To build the output circuit of the route.

5. To plot the graph of simulation results.

In order to select the most effective method for solving the problem of optimizing of road transport movement in the delivery of goods (based on the Traveling Salesman Problem), an algorithm and a computer program were developed in Delphi 7. The program solves the problem based on the following methods and algorithms: Greedy Approach, Modified Greedy Approach, Minimum Spanning Tree, Monte Carlo Simplification Model, Ant Colony Optimization, Algorithm of Little. The route calculation can be carried out for 100 points in the route. For comparative analysis, calculations were made for 40 points of the route, based on the physical meaning of the problem. The calculations were performed on a personal computer IntelCore i5-3470 3.2 GHz, with 4GB RAM with Windows 8.1 (x64) operating system. The time parameters of calculations based on the previously mentioned algorithms were also evaluated.

Figure 1 shows the simulation results.

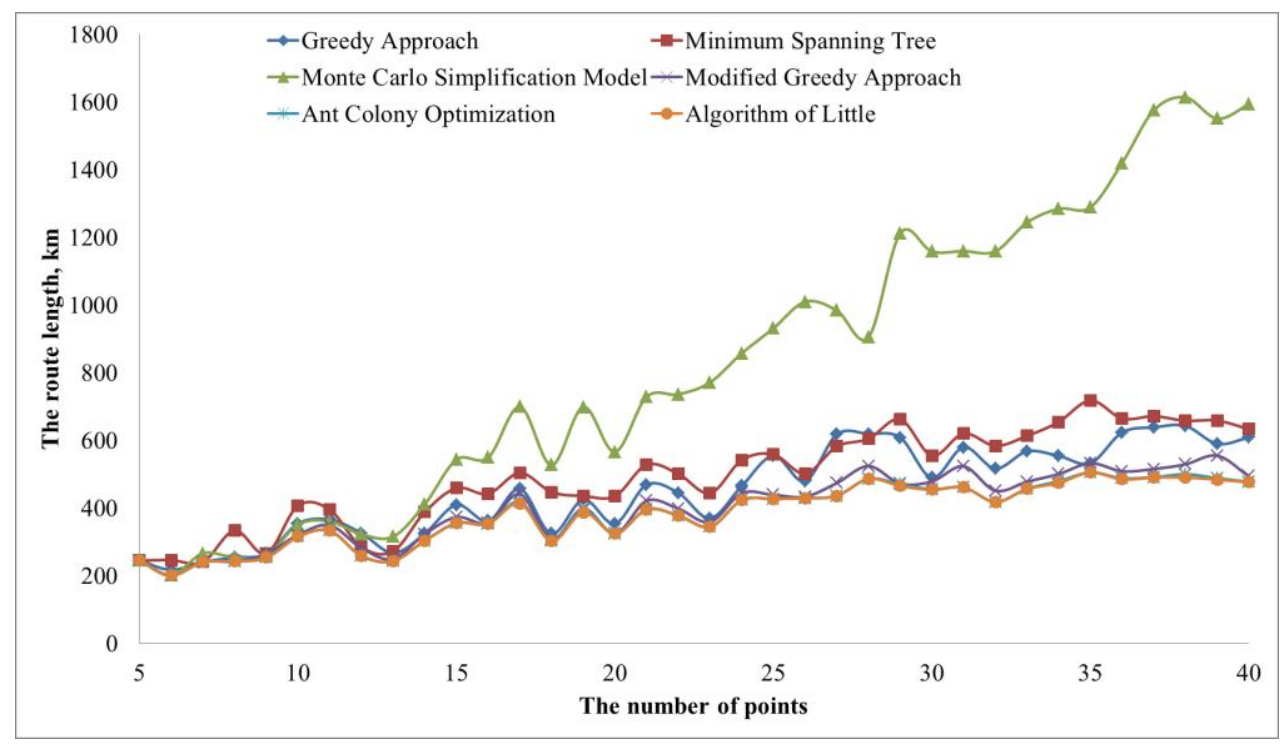

Fig. 1. The results of simulation of different algorithms for solving the Traveling Salesman Problem.

The Algorithm of Little showed the best result. If the number of points is small (less than $15)$, it is one of the most effective algorithms, and when the number of points of the route increases, it becomes the best. At the same time, it requires more computing resources than other algorithms. In second place is the Ant Colony Optimization. Modified Greedy Approach is more effective than the Greedy Approach (by 37\%), but its operation time is several times longer. It is not recommended to use the Monte Carlo Simplification Model, because its performance is worse than other algorithms considered. The computation time of the Monte Carlo Simplification Model, Minimum Spanning Tree, Greedy Approach and Modified Greedy Approach is about the same and almost equal to zero. The Algorithm of Little and the Ant Colony Optimization spend more time in computation in comparison with these algorithms, but even it does not exceed $1 \mathrm{~s}$.

So, for the solution of the considered problem can be used the Algorithm of Little and the Ant Colony Optimization. It should be noted that they have another advantage over other 
algorithms studied - it is no need to improve the routes obtained with their help. Therefore, to solve the problem of optimizing of road transport movement in the delivery of goods, it is recommended to use the Algorithm of Little and the Ant Colony Optimization.

\section{Results section}

As an example was considered the case of transportation of goods by vehicle from a warehouse located on the outskirts of the city with a population of about 130 thousand people (Kolomna, Moscow region) to stores (supermarkets of the trading network "Magnit"). Total points of the route is $n=14$, where $n=1$ is warehouse - the beginning of the route, the remaining points of the route are stores. The coordinates of points were defined using the satellite map. Possible delays due to road conditions (traffic lights, traffic jams, etc.) were taken into account when calculating the distances in the form of factors that extend the routes.

Using the developed computer program "Traveling Salesman Problem" was calculated the distance matrix between the route points (Table 1).

Table 1. The distance matrix between the route points.

\begin{tabular}{|c|c|c|c|c|c|c|c|c|c|c|c|c|c|c|c|c|}
\hline & \multicolumn{10}{|c|}{ Distance coverage, $\mathrm{km}$} \\
\hline & $\mathbf{1}$ & $\mathbf{2}$ & $\mathbf{3}$ & $\mathbf{4}$ & $\mathbf{5}$ & $\mathbf{6}$ & $\mathbf{7}$ & $\mathbf{8}$ & $\mathbf{9}$ & $\mathbf{1 0}$ & $\mathbf{1 1}$ & $\mathbf{1 2}$ & $\mathbf{1 3}$ & $\mathbf{1 4}$ & $\mathbf{1 5}$ & $\mathbf{1 6}$ \\
\hline $\mathbf{1}$ & 0.0 & 3.2 & 2.8 & 5.4 & 6.6 & 1.3 & 2.1 & 3.0 & 4.7 & 4.1 & 3.5 & 3.2 & 1.8 & 3.5 & 3.2 & 3.1 \\
\hline $\mathbf{2}$ & 3.2 & 0.0 & 0.4 & 3.4 & 4.8 & 2.6 & 3.0 & 1.0 & 3.0 & 0.4 & 1.3 & 1.0 & 2.1 & 2.0 & 1.0 & 0.9 \\
\hline $\mathbf{3}$ & 2.8 & 0.4 & 0.0 & 3.0 & 4.4 & 2.2 & 2.6 & 0.6 & 2.6 & 0.8 & 1.7 & 1.4 & 1.7 & 2.4 & 0.6 & 0.5 \\
\hline $\mathbf{4}$ & 5.4 & 3.4 & 3.0 & 0.0 & 1.4 & 4.1 & 1.1 & 2.3 & 0.6 & 3.6 & 4.6 & 4.3 & 4.0 & 5.7 & 3.5 & 3.4 \\
\hline $\mathbf{5}$ & 6.6 & 4.8 & 4.4 & 1.4 & 0.0 & 5.5 & 2.5 & 3.7 & 2.0 & 5.0 & 6.0 & 5.7 & 5.4 & 7.1 & 4.9 & 4.8 \\
\hline $\mathbf{6}$ & 1.3 & 2.6 & 2.2 & 4.1 & 5.5 & 0.0 & 3.8 & 1.8 & 3.8 & 2.8 & 2.3 & 2.0 & 0.8 & 2.5 & 1.9 & 2.0 \\
\hline $\mathbf{7}$ & 2.1 & 3.0 & 2.6 & 1.1 & 2.5 & 3.8 & 0.0 & 2.0 & 0.7 & 3.3 & 4.3 & 4.0 & 3.7 & 5.4 & 3.2 & 3.1 \\
\hline $\mathbf{8}$ & 3.0 & 1.0 & 0.6 & 2.3 & 3.7 & 3.8 & 2.0 & 0.0 & 2.0 & 1.3 & 2.3 & 2.0 & 1.7 & 3.4 & 1.2 & 1.1 \\
\hline $\mathbf{9}$ & 4.7 & 3.0 & 2.6 & 0.6 & 2.0 & 2.8 & 0.7 & 2.0 & 0.0 & 3.3 & 4.3 & 4.0 & 3.7 & 5.4 & 3.2 & 3.1 \\
\hline $\mathbf{1 0}$ & 4.1 & 0.4 & 0.8 & 3.6 & 5.0 & 2.3 & 3.3 & 1.3 & 3.3 & 0.0 & 0.9 & 0.6 & 2.2 & 1.6 & 1.0 & 1.1 \\
\hline $\mathbf{1 1}$ & 3.5 & 1.3 & 1.7 & 4.6 & 6.0 & 2.0 & 4.3 & 2.3 & 4.3 & 0.9 & 0.0 & 0.3 & 1.8 & 0.8 & 0.4 & 0.5 \\
\hline $\mathbf{1 2}$ & 3.2 & 1.0 & 1.4 & 4.3 & 5.7 & 1.7 & 4.0 & 2.0 & 4.0 & 0.6 & 0.3 & 0.0 & 1.5 & 0.1 & 0.7 & 0.8 \\
\hline $\mathbf{1 3}$ & 1.8 & 2.1 & 1.7 & 4.0 & 5.4 & 0.8 & 3.7 & 1.7 & 3.7 & 2.2 & 1.8 & 1.5 & 0.0 & 1.7 & 1.3 & 1.4 \\
\hline $\mathbf{1 4}$ & 3.5 & 2.0 & 2.4 & 5.7 & 7.1 & 2.5 & 5.4 & 3.4 & 5.4 & 1.6 & 0.8 & 1.7 & 1.7 & 0.0 & 1.6 & 1.7 \\
\hline $\mathbf{1 5}$ & 3.2 & 1.0 & 0.6 & 3.5 & 4.9 & 1.9 & 3.2 & 1.2 & 3.2 & 1.0 & 0.4 & 0.7 & 1.3 & 1.6 & 0.0 & 0.1 \\
\hline $\mathbf{1 6}$ & 3.1 & 0.9 & 0.5 & 3.4 & 4.8 & 2.0 & 3.1 & 1.1 & 3.1 & 1.1 & 0.5 & 0.8 & 1.4 & 1.7 & 0.1 & 0.0 \\
\hline
\end{tabular}

To determine the shortest route of vehicle movement was chosen Algorithm of Little, based on the considerations discussed earlier. As the result of the calculations was obtained following the shortest route: 1-6-7-3-4-5-2-8-13-14-11-9-12-10-1; the length of the route $23680 \mathrm{~m}$. The scheme of the route obtained on the basis of Algorithm of Little, is presented in figure 2 . 


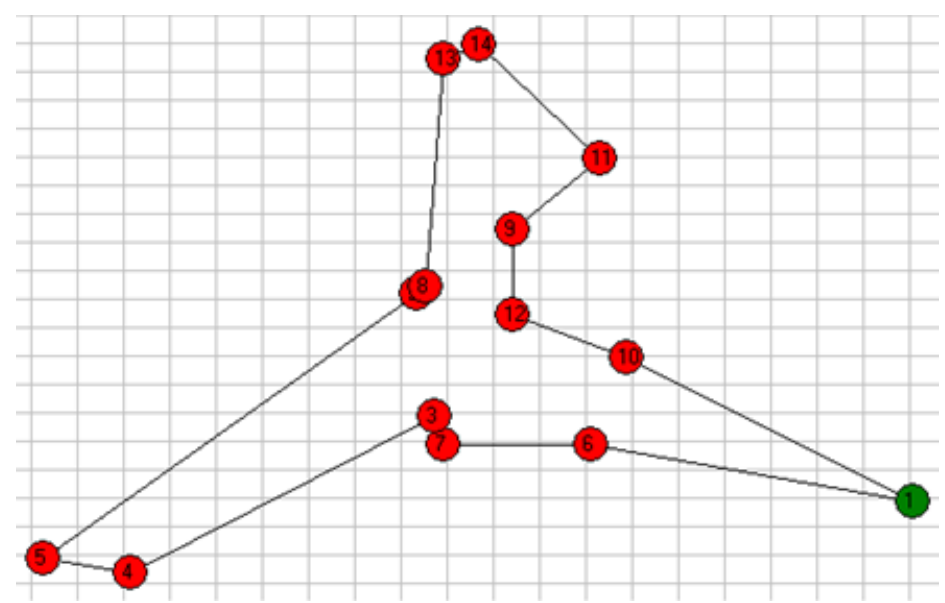

Fig. 2. The scheme of the route obtained on the basis of algorithm of Little.

On the one hand, the vehicle can drive this distance (about $24 \mathrm{~km}$ ) for 0.5 hours, moving at an average speed of $50 \mathrm{~km} / \mathrm{h}$. On the other hand, taking into account the time of unloading goods in 13 stores (about 0.5 hours in each store), the delivery of goods will take about 7 hours. This may not be beneficial in terms of timely delivery of goods. In this case, the head of the chain stores can increase the number of vehicles and release them on the route at the same time. To determine the points of the retail network, where it is necessary to send another vehicle, it is enough to analyze the resulting scheme and distance matrix and using the program to make the best routes for each of the vehicles separately.

\section{Conclusions}

The proposed approach to solving the problem of optimizing of road transport movement in the delivery of goods can reduce the time for their transportation and to conduct a rational distribution of vehicles. This will reduce the required number of vehicles involved in these transportations, and, consequently, reduce operating costs for the maintenance of vehicles (reducing the consumption of fuel and lubricants, spare parts, reducing the mileage of the vehicles per shift, etc.), as well as reduce the cost of maintenance of personnel. Developed in the course of the research algorithm and computer program can be used not only in transport logistics, but also in other areas of the economy.

\section{References}

1. M.T. Dzhons, The programming of artificial intelligence applications: monograph (DMK Press, Moskow, 2004)

2. J. Li, Q. Sun, M.C. Zhou, X. Yu, X. Dai, IFAC Proc. 47(3), 9575-9580 (2014)

3. E. Malaguti, S. Martello, A. Santini, Omega 74, 50-58 (2018)

4. A.V. Tarasova, News of Higher Edu. Inst. Eng. 5, 71-76 (2005)

5. J. Xua, L. Peia, R. Zhub, Proc. Comp. Science 131, 937-945 (2018)

6. I.R. Kafiev, P.S. Romanov, I.P. Romanova, Rus. Electr. Scient. J. 8(14), 11-24 (2014)

7. I. Kafiev, P. Romanov, I. Romanova, Bull. Bashkir Univ. 3(35), 48-52 (2015)

8. T.H. Kormen, CH.I. Lejzerson, R.L. Rivest, K. Shtajn, Algorithms: construction and analysis: monograph (Williams, Moscow, 2016) 
9. G. Mac Connell, The foundations of modern algorithms: monograph (Technosphere, Moscow, 2004)

10. H.A. Taha, Introduction to operations research: monograph (Williams, Moscow, 2005)

11. V.V. Burkhovetskiya, B. Y. Steinberga, Proc. Comp. Science 119, 97-102 (2017)

12. X. Baoa, Z. Liub, W. Yub, G. Lic, Inf. Proc. Let. 127, 54-57 (2017)

13. M. Mestria, Comp. Ind. Eng. 116, 1-12 (2018)

14. E. Baidoo, S.O. Oppong, Int. J. of Comp. Appl. 152 (8), 13-19 (2016)

15. C. Doppstadta, A.Kobersteinb, D. Vigoc, Eur. J. of Oper. Res. 253(3), 825-842 (2016)

16. Chentsov, M. Khachay, D. Khachay, IFAC-PapersOnLine 49(2), 651-655 (2016) 